\title{
Investigation into COD Component in the Wastewater at Sea Reclamation Waste Disposal Site and Its Influence on the Coagulation-Sedimentation and the Activated Carbon Adsorption
}

\author{
Chen Huang ${ }^{1}$, Seiichi Ishikawa ${ }^{1,}$ *, Wei Xie ${ }^{1}$, Mahmoud Abuobiedah ${ }^{1}$, Syun Tomita ${ }^{2}$, Kiyoshi Mitsui ${ }^{3}$, \\ Junji Nakanishi $^{3}$, Teiji Tanizaki ${ }^{4}$, Jian Huang ${ }^{5}$ \\ ${ }^{1}$ Graduate School of Environmental Engineering, The University of Kitakyushu, Kitakyushu City, Japan \\ ${ }^{2}$ Faculty of Environmental Engineering, The University of Kitakyushu, Kitakyushu City, Japan \\ ${ }^{3}$ Hibikinada Development Co. LTD., Kitakyushu City, Japan \\ ${ }^{4}$ Environmental Bureau, Kitakyushu City Hall, Kitakyushu City, Japan \\ ${ }^{5}$ Institute for Global Environmental Strategies, Kanagawa, Japan
}

Email address:

huangchen19872015@163.com (C. Huang),ishikawa@kitakyu-u.ac.jp (S. Ishikawa), xierlly@yahoo.co.jp (W. Xie), abujapan1@hotmail.com (M. Abuobiedah),s1511029@eng.kitakyu-u.ac.jp (S. Tomita), j.nakanishi@hibikidev.co.jp (J. Nakanishi), tanizaki.t@gmail.com (T. Tanizaki), huang@iges.or.jp (J. Huang)

${ }^{*}$ Corresponding author

\section{To cite this article:}

Chen Huang, Seiichi Ishikawa, Wei Xie, Mahmoud Abuobiedah, Syun Tomita, Kiyoshi Mitsui, Junji Nakanishi, Teiji Tanizaki, Jian Huang. Investigation into COD Component in the Wastewater at Sea Reclamation Waste Disposal Site and Its Influence on the Coagulation-Sedimentation and the Activated Carbon Adsorption. American Journal of Civil Engineering. Vol. 4, No. 4, 2016 , pp. 198-204. doi: 10.11648/j.ajce.20160404.20

Received: June 15, 2016; Accepted: July 7, 2016; Published: July 11, 2016

\begin{abstract}
The relationship between COD component and the Coagulation-Sedimentation or the activated carbon adsorption, which were performed at the existing effluent water treatment facility, was investigated effectively to treat COD of the wastewater at the sea reclamation waste disposal site. COD could decrease by only bubbling because COD except for organic matters was contained in waste and wastewater. It is effective to measure the ion property of organic-COD in some waste and select an adequate coagulant. However, it was not necessary that the ion property was related to COD removal ratio. In the activated carbon adsorption, the batch method was very effective but it is necessary to examine the solid-liquid separation after the treatment. Besides, the classification of disposal site for COD treatment and the introduction of the additional charge system calculated on the effluent treatment cost were considered.
\end{abstract}

Keywords: Sea Reclamation Waste Disposal Site, Leachate, COD Component, Coagulation-Sedimentation, Activated Carbon Adsorption

\section{Introduction}

Various wastes as sludge or cinder are carried and are reclaimed at a reclamation waste disposal site in proportion to the variety and the complication of industry. Then, it is considered that hardly degradable organic matters, metals and chemical substances exist in leachate. In fact, COD concentration of wastewater at Hibikinada reclamation waste disposal site in Kitakyushu City becomes over $100 \mathrm{mg} \mathrm{L}^{-1}$ at the end of reclamation and it is difficult to decrease at below $20 \mathrm{mg} \mathrm{L}^{-1}$ (aiming value) by the existing effluent treatment (contact oxidation - the Coagulation-Sedimentation with $\mathrm{FeCl}_{3}$ - sand filtration - particulate activated carbon adsorption). As this countermeasure, the pile construction [1], the Coagulation-Sedimentation with powder activated carbon, the penetration of wastewater into the reclaimed wastes $[2,3]$ 
and the purification by a little stream [4] were examined. But, they were not practical. The reason is considered that the COD components in wastes can be hardly treated with normal coagulant or activated carbon.

Then, we examined COD and total organic carbon (TOC) in 9 kinds of wastes which were carried and reclaimed at the disposal site and contained high concentration of COD. The relationships between the COD components in 6 kinds of wastes and the Coagulation-Sedimentation or the activated carbon adsorption were examined. Further, we also examined the selection and the design of appropriate coagulant or activated carbon and the prospective system for the acceptance of waste.

\section{Materials and Methods}

\subsection{Reagents}

The strong acid cation-exchange resin and the strong basic anion-exchange resin were a Wako Pure Chemical Industrials Dowex 50Wx8 (100-200 mesh) and a Dowex 1x8 (100-200 mesh), respectively.

$\mathrm{FeCl}_{3}$ anhydride and polyaluminum chloride (PAC) were obtained from Wako Pure Chemical Industries and Kurosaki Chemical Industry, respectively. The strong cation-polymer coagulant, the nonion-polymer coagulant, the strong anion-polymer coagulant and the inorganic nonion-coagulant were a MT Aqua Polymer Aronfloc C-508 (polyacrylic ester), a Accofloc N-100S (polyacrylamide), an Accofloc A-150 (polyacrylamide) and a Noatech Supernammit, respectively.

The granular activated carbons were a Taihei Chemical Industrial Yashicoal S.SC, a Yashicoal M.MC, a Yashicoal L.LC, a Procoal CM and a Procoal GN. Their properties were shown in Table 1.

The standard molecular weight reagents were a VARIAN PL 2070-0100 (polyethylene glycol; molecular weight: 106-21,030) and a PL 2080-0101 (polyethylene oxide; molecular weight: 15,120-859,500). Other reagents were equally with JIS K 0102 [5]. The pure water was purified using a Japan Millipore Milli-Q SP.

Table 1. Properties of each activated carbon.

\begin{tabular}{llllll}
\hline & Yashicoal & Yashicoal & Yashicoal & Procoal & Procoal \\
\cline { 2 - 6 } & S.SC & M.MC & L.LC & CM & GN \\
\hline Material & Coconut shell & Coconut shell & Coconut shell & Coal & Coal \\
Activation & Steam & Steam & Steam & Steam & Steam \\
Drying loss $(\%)$ & 3.9 & 1.5 & 2.6 & 2.0 & 0.5 \\
Particle size $(\mathrm{mm})$ & $0.50-0.25$ & $2.36-0.50$ & $4.75-2.36$ & $2.36-0.50$ & $4.75-3.35$ \\
Infill rate $\left(\mathrm{g} \mathrm{mL}^{-1}\right)$ & 0.48 & 0.47 & 0.49 & 0.43 & 0.46 \\
Specific surface area $\left(\mathrm{m}^{2} \mathrm{~g}^{-1}\right)$ & 1,050 & 1,157 & 960 & 1,137 & 1,228 \\
Average fine pore size $(\AA)$ & 17.9 & 18.4 & 17.8 & 20.0 & 18.7 \\
Fine pore volume $\left(\mathrm{cm}^{3} \mathrm{~g}^{-1}\right)$ & 0.469 & 0.532 & 0.428 & 0.570 & 0.574 \\
$\mathrm{I}_{2}$-adsorption $\left(\mathrm{mg} \mathrm{g}^{-1}\right)$ & 1,200 & 1,140 & 1,100 & 1,080 & 1,100 \\
Benzene-adsorption $(\%)$ & 36.9 & 34.8 & 34.1 & 35.3 & 36.1 \\
Methylene blue-adsorption $\left(\mathrm{mL} \mathrm{g}^{-1}\right)$ & 220 & 200 & 200 & & 190 \\
\hline
\end{tabular}

\subsection{Instruments}

$\mathrm{pH}$ meter and electric conductivity (EC) meter were a Horiba F-53 and a Toa Electronics CM-40S, respectively. TOC meter was a Shimadzu TOC-5000/an auto sampler ASI-5000A. Spectrophotometer was a JASCO NQF-720/U-630. Atomic absorption spectrometer (AAS) was a Varian AA240 FS. Ion chromatograph was a Nippon Dionex/an auto sampler DAS-80/a Shimadzu column oven CTO-10A. Jar tester was a Miyamoto Riken Industries JT-6D.

\subsection{Samples}

\subsubsection{Wastewater at the Disposal Site}

To investigate the wastewater at the disposal site, 2 drilling hole waters were sampled in December 2011.

\subsubsection{Carried Waste}

Above 10 kinds of wastes containing high concentration of COD are carried and are reclamated at the disposal site. Incineration residue of domestic waste (incineration plant),
Sludge A (intermediate waste treatment) and Sludge B (intermediate waste treatment) were collected in May 2009. Slag A (casting sand), Slag D (containing binder) and Dust (chelating and containing cement) were collected in June 2011. Other wastes were collected in 2008-2011.

\subsection{Elution Test}

The elution tests for Sludge $\mathrm{C}$ (intermediate waste treatment)), Cinder A (incineration ash), Cinder B (chelating), Slag A, Slag B (casting sand) and Slag C (casting sand) were also done and COD and TOC were measured. The elution test was equally performed with "the Verification Methods for Metals et. al. Contained in Industrial Waste" [6]. The ratio of waste (dry matter) and purified water or sea water was $3 \mathrm{w}$ $\mathrm{v}^{-1} \%$ and the mixture was shaken for $6-\mathrm{h}$.

\subsection{Preparation of Test Solution}

As the test solution for the component examination of COD, total nitrogen (T-N) and total phosphorous (T-P), the Coagulation-Sedimentation and the activated carbon 
adsorption, $0.5 \mathrm{~kg}$ of waste was mixed with $17 \mathrm{~L}$ of purified water, the mixture was stand for a day and the supernatant was filtrated with a $1 \mu \mathrm{m}$ glass fiber filter paper (GFP).

\subsection{Bubbling}

The bubbling for $50 \mathrm{~mL}$ of test solution was done at 200 $\mathrm{mL} \mathrm{min}^{-1}$ for 30-min and COD and inorganic-COD were measured by the method in 2.9.1.

\subsection{Coagulation-Sedimentation}

\subsubsection{Coagulation-Sedimentation with Several Kinds of Coagulant}

Each $500 \mathrm{~mL}$ of the test solution prepared in 5 was placed in 6 of $1 \mathrm{~L}$ beaker and each $0-100 \mathrm{mg} \mathrm{L}^{-1}$ of coagulant was added. The prepared solutions were rapidly mixed for 1-min at $150 \mathrm{rpm}$ and then were slowly stirred for 10-min at $50 \mathrm{rpm}$ with a jar tester. After 30-min of quiescent settling, the supernatant was filtrated with a $1 \mu \mathrm{m}$ GFP and the filtrate was analyzed.

\subsubsection{Influence of Rapid Mixture}

For Sludge A, the removal ratio was examined with $50 \mathrm{mg}$ $\mathrm{L}^{-1}$ of $\mathrm{FeCl}_{3}$ at $0-350 \mathrm{rpm}$ of rapid mixture. The Coagulation-Sedimentation was performed at the best $\mathrm{pH}$.

\subsubsection{Influence of Anion}

For Sludge A, the influence of anion was examined with $50 \mathrm{mg} \mathrm{L}^{-1}$ of $\mathrm{FeCl}_{3}$ by adding $0-2.0 \mathrm{~g}$ of $\mathrm{NaCl}$ or $0-2.96 \mathrm{~g}$ of $\mathrm{Na}_{2} \mathrm{SO}_{4}$.

\subsection{Activated Carbon Adsorption}

\subsubsection{Adsorption with a Column}

The glass chromatocolumn (the inside diameter: $1 \mathrm{~cm}$; length: $30 \mathrm{~cm}$ ) was packed with $3 \mathrm{~g}$ of activated carbon and was washed with $400 \mathrm{~mL}$ of purified water. One hundred milliliter of test solution (TOC: $10 \mathrm{mg} \mathrm{L}^{-1}$ ) was path through the column and the adsorption ratio of TOC was calculated.

For the adsorption of metal ions, each $100 \mathrm{~mL}$ of $\mathrm{Ni}^{+}$and $\mathrm{Fe}^{3+}$ solution $\left(10 \mathrm{mg} \mathrm{L}^{-1}\right)$ was prepared. The solution was used for the column test.

\subsubsection{Adsorption with a Jar Tester}

Each $500 \mathrm{~mL}$ of $\mathrm{Ni}^{+}$and $\mathrm{Fe}^{3+}$ solution $\left(10 \mathrm{mg} \mathrm{L}^{-1}\right)$ was placed in 6 of $1 \mathrm{~L}$ beaker and each $3 \mathrm{~g}$ of activated carbon was added. The prepared solutions were rapidly mixed for $1-\mathrm{min}$ at $150 \mathrm{rpm}$ and then were slowly stirred for $10-\mathrm{min}$ at $50 \mathrm{rpm}$. After 30-min of quiescent settling, the supernatant was filtrated with a $1 \mu \mathrm{m}$ GFP and the filtrate was analyzed.

\subsection{Analytical Methods}

\subsection{1. $C O D$ and Inorganic-COD}

COD was measured by JIS K 0102 [5]. COD value contains the inorganic reducing matters as $\mathrm{H}_{2} \mathrm{~S}$, metals, etc. These matters were easy to be oxidized with $\mathrm{KMnO}_{4}$. Then, we defined the COD without 30 -min of heating as the inorganic-COD.

\subsubsection{Ionic Properties of COD, TOC, T-N and T-P}

The glass chromatocolumn (the inside diameter: $3 \mathrm{~cm}$; length: $40 \mathrm{~cm}$ ) was packed with $200 \mathrm{~mL}$ of the strong acid cation-exchange resin and was washed twice with $200 \mathrm{~mL}$ of $1 \mathrm{~N} \mathrm{HCl}, 200 \mathrm{~mL}$ of purified water, $200 \mathrm{~mL}$ of $1 \mathrm{~N} \mathrm{NaOH}$ and $200 \mathrm{~mL}$ of purified water in turn. In the same way, the chromatocolumn was packed with $200 \mathrm{~mL}$ of the strong basic anion-exchange resin and was washed twice with $200 \mathrm{~mL}$ of $1 \mathrm{~N} \mathrm{NaOH}, 200 \mathrm{~mL}$ of purified water, $200 \mathrm{~mL}$ of $1 \mathrm{~N} \mathrm{HCl}$ and $200 \mathrm{~mL}$ of purified water in turn. One hundred milliliter of test solution prepared in 5 was path through each column at $20 \mathrm{~mL} \mathrm{~min}^{-1}$, each decreased concentration of COD, T-N and T-P were measured and each ratio of cation, nonion and anion was calculated.

\subsubsection{Waste and Water Quality}

Water content and ignition loss (IL) were measured by Guideline for Lake Environmental Survey [7]. pH, EC, COD, TOC, T-N, T-P, F', $\mathrm{Br}^{-}, \mathrm{Cl}^{-}$and $\mathrm{SO}_{4}{ }^{2-}$ were measured by JIS K 0102 [5].

\section{Results and Discussion}

\subsection{Water Quality of Leachate}

\subsubsection{Drilling Hole Water}

The COD values of Drilling hole water A and Drilling hole water $\mathrm{B}$ were 125 and $196 \mathrm{mg} \mathrm{L}^{-1}$, respectively. The ratios of inorganic-COD were 17.6 and $38.8 \%$, respectively (Fig. 1). By bubbling for 30-min, the inorganic-COD in Drilling hole water B was removed. Forty point eight percent of nonion organic-COD was contained in Drilling hole water A. Twenty four percent of cation organic-COD and $22.4 \%$ of anion organic-COD were contained in Drilling hole water B. The ratios for TOC were nearly same as those for COD (Fig. 2).

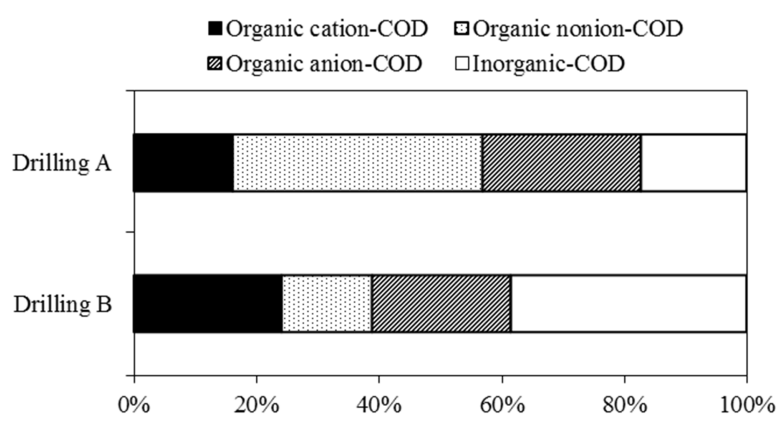

Fig. 1. Component ratio of $C O D$ in the drilling hole water.

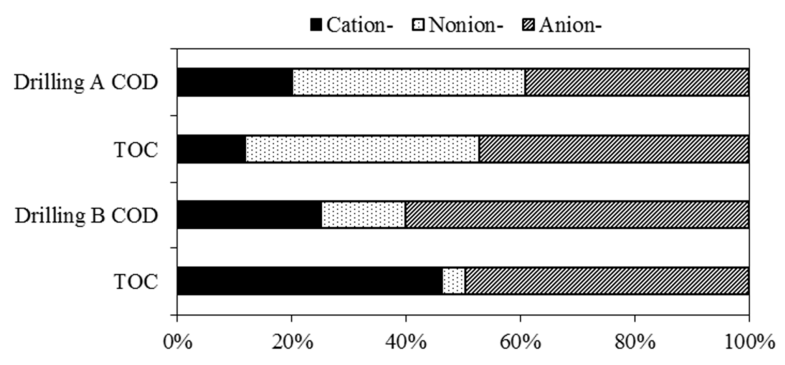

Fig. 2. Component ratios of $C O D$ and TOC in the drilling hole water. 


\subsubsection{Elution Test for Carried Waste}

Table 2 showed the results of COD and TOC in the elution test with sea water for 6 wastes containing large amount of organic matters. The COD values were 50.2 (Cinder A) - 480 $\mathrm{mg} \mathrm{L}^{-1}$ (Slag C) and the TOC values were 40.6 (Cinder B) $740 \mathrm{mg} \mathrm{L}^{-1}$ (Slag C). The ratios of COD/TOC were 0.65 (Slag C) - 1.9 (Sludge C).

The results of the elution tests with purified water for Incineration residue of domestic waste, Sludge A and Sludge $\mathrm{B}$ were shown in Table 3. $\mathrm{pH}$ was 9.52-10.1. Ten point nine milligrams per liter of T-N and $1.52 \mathrm{mg} \mathrm{L}^{-1}$ of T-P eluted from Sludge A at high concentration. High concentration of $\mathrm{Cl}^{-}\left(1,230\right.$ and $\left.105 \mathrm{mg} \mathrm{L}^{-1}\right)$ and $\mathrm{SO}_{4}{ }^{2-}\left(710\right.$ and $\left.570 \mathrm{mg} \mathrm{L}^{-1}\right)$ eluted from Incineration residue of domestic waste and Sludge B, respectively. High concentration of $\mathrm{F}^{-}\left(9.9 \mathrm{mg} \mathrm{L}^{-1}\right)$, $\mathrm{Br}^{-}\left(1,650 \mathrm{mg} \mathrm{L}^{-1}\right), \mathrm{Cl}^{-}\left(3,330 \mathrm{mg} \mathrm{L}^{-1}\right)$ and $\mathrm{SO}_{4}{ }^{2-}(1,870 \mathrm{mg}$ $\mathrm{L}^{-1}$ ) eluted from Sludge A. Then, the EC level (131-930 mS $\mathrm{m}^{-1}$ ) of these wastes was high.

\subsubsection{Component Ratios of COD, TOC, T-N and T-P in the Carried Waste}

Table 2. Results of the elution test for the wastes containing large amount of organic matters.

\begin{tabular}{lllllll}
\hline & Sludge C & Cinder A & Cinder B & Slag A & Slag B & \\
\hline COD $\left(\mathrm{mg} \mathrm{L}^{-1}\right)$ & 100 & 50.2 & 73.1 & 245 & 220 \\
TOC $\left(\mathrm{mg} \mathrm{L}^{-1}\right)$ & 53.3 & 47.8 & 40.6 & 260 & 290 \\
COD/TOC & 1.9 & 1.1 & 1.8 & 0.94 & 0.76 \\
\hline
\end{tabular}

Table 3. Results of the elution test for the wastes.

\begin{tabular}{|c|c|c|c|}
\hline & Incineration residue of domestic waste & Sludge A & Sludge B \\
\hline Water content $(\%)$ & 9.0 & 27.6 & 18.9 \\
\hline IL (\%) & 5.2 & 19.8 & 6.7 \\
\hline $\mathrm{pH}$ & 10.0 & 10.1 & 9.52 \\
\hline $\mathrm{EC}\left(\mathrm{mS} \mathrm{m}^{-1}\right)$ & 370 & 930 & 131 \\
\hline $\operatorname{COD}\left(\mathrm{mg} \mathrm{L}^{-1}\right)$ & 30.9 & 48.5 & 15.6 \\
\hline TOC (mg L $\left.{ }^{-1}\right)$ & 26.4 & 94.9 & 4.9 \\
\hline $\mathrm{COD} / \mathrm{TOC}$ & 1.2 & 0.51 & 3.2 \\
\hline $\mathrm{T}-\mathrm{P}\left(\mathrm{mg} \mathrm{L}^{-1}\right)$ & 0.60 & 1.52 & 0.57 \\
\hline $\mathrm{T}-\mathrm{P} / \mathrm{T}-\mathrm{N}$ & 1.5 & 0.14 & 0.62 \\
\hline $\mathrm{F}^{-}\left(\mathrm{mg} \mathrm{L}^{-1}\right)$ & 0.9 & 9.9 & 1.4 \\
\hline $\mathrm{Br}^{-}\left(\mathrm{mg} \mathrm{L}^{-1}\right)$ & 3.9 & 1,650 & 2.6 \\
\hline $\mathrm{Cl}^{-}\left(\mathrm{mg} \mathrm{L}^{-1}\right)$ & 1,230 & 3,330 & 105 \\
\hline $\mathrm{SO}_{4}{ }^{2-}\left(\mathrm{mg} \mathrm{L}^{-1}\right)$ & 710 & 1,870 & 570 \\
\hline
\end{tabular}

Figure 3 showed the component ratios of $\mathrm{COD}$ in Incineration residue of domestic waste, Sludge A and Sludge B. Thirteen point four to $33.5 \%$ of inorganic-COD was contained. Incineration residue of domestic waste contained much organic cation-COD (43.2\%) but Sludge A (2.2\%) and Sludge B (3.1\%) contained small amount of organic cation-COD. As the reclamation ratio at the disposal site was about $40 \%$ of incineration residue of domestic waste, about $30 \%$ of construction waste and about $10 \%$ of sludge, the drilling hole water contained relatively large amount of organic cation-COD. Sludge A and Sludge B contained much nonion-COD (29.4 and 30.9\%, respectively). Anion-COD was $33.8-36.1 \%$.

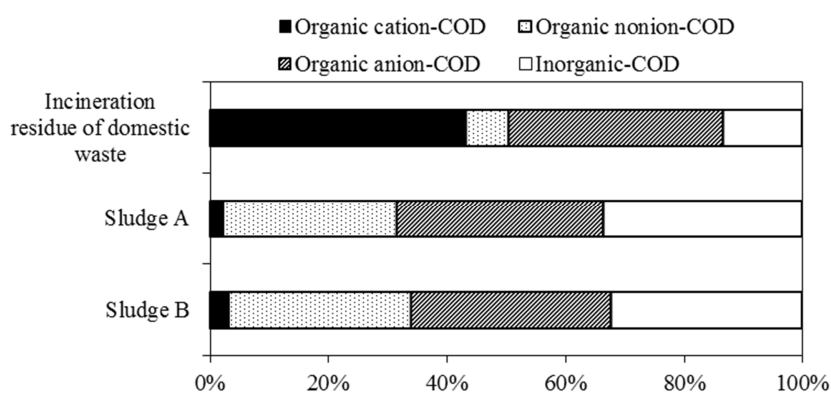

Fig. 3. Component ratio of $C O D$ in the carried waste.

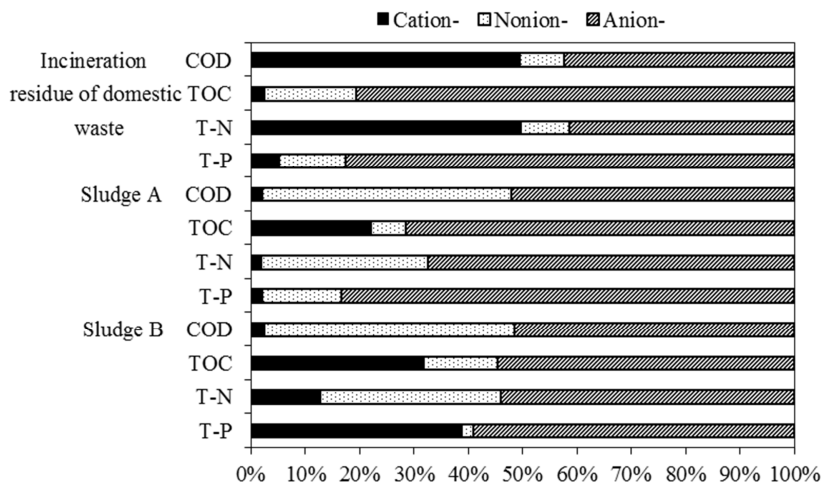

Fig. 4. Component ratios of COD, TOC, T-N and T-P in the carried waste.

Figure 4 showed the component ratio of COD, TOC, T-N and T-P. The ratio of TOC was different from that of COD. In Incineration residue of domestic waste, cation-TOC $(2.5 \%)$ was a little and nonion-TOC (16.9\%) or anion-TOC (80.6\%) was much. In Sludge A and Sludge B, nonion-TOC (6.5 and $13.6 \%$, respectively) was a little and cation-TOC (22.1 and $31.8 \%$, respectively) or anion-TOC (71.4 and $54.6 \%$, respectively) was much. Generally, the part of $\mathrm{N}$ becomes cation and the part of $\mathrm{P}$ becomes anion. In Incineration residue of domestic waste, cation-T-N (49.7\%) or anion-T-N (41.4\%) was much and nonion-T-N (8.9\%) was a little. In 
Sludge A and Sludge B, cation-T-N (1.9 and 12.8\%, respectively) was a little and nonion-T-N (30.8 and 33.3\%, respectively) or anion-T-N (67.3 and 53.9\%, respectively) was much. As for T-P, cation-T-P (5.2 and 2.1\%, respectively) was a little in Incineration residue of domestic waste and Sludge A. In Sludge B, cation-T-P (38.8\%) was much.

Table 4. Change (\%) of COD by bubbling.

\begin{tabular}{|c|c|c|c|c|c|}
\hline & Incineration residue of domestic waste & Sludge A & Sludge B & Slag C & Slag D \\
\hline Inorganic-COD & 13.4 & 33.5 & 32.2 & 14.4 & 40.8 \\
\hline COD after bubbling & 93.5 & 106 & 119 & 100 & 91.7 \\
\hline Change of COD by bubbling & -6.5 & +6 & +19 & 0 & -8.3 \\
\hline
\end{tabular}

Table 5. Maximum removal ratio (\%) with each coagulant.

\begin{tabular}{|c|c|c|c|c|c|c|c|}
\hline & & \multirow{2}{*}{$\mathrm{FeCl}_{3}$} & \multirow{2}{*}{ PAC } & \multirow{2}{*}{$\begin{array}{l}\text { Aronfloc } \\
\text { C-508 }\end{array}$} & \multicolumn{2}{|l|}{ Accofloc } & \multirow{2}{*}{ Supernammit } \\
\hline & & & & & $\mathrm{N}-100 \mathrm{~S}$ & A-150 & \\
\hline \multirow{4}{*}{$\begin{array}{l}\text { Incineration residue of } \\
\text { domestic waste }\end{array}$} & COD & 22 & 37 & 27 & 19 & 17 & 26 \\
\hline & TOC & 24 & 28 & 25 & 6 & 16 & 27 \\
\hline & $\mathrm{T}-\mathrm{N}$ & 31 & 34 & 44 & 22 & 28 & 14 \\
\hline & T-P & 25 & 38 & 22 & 31 & 27 & 11 \\
\hline \multirow{4}{*}{ Sludge A } & COD & 18 & 24 & 7 & 35 & 12 & 10 \\
\hline & TOC & 4 & 9 & 7 & 16 & 9 & 11 \\
\hline & $\mathrm{T}-\mathrm{N}$ & 8 & 5 & 14 & 28 & 27 & 4 \\
\hline & T-P & 7 & 10 & 12 & 21 & 22 & 5 \\
\hline \multirow{4}{*}{ Sludge B } & COD & 16 & 29 & 18 & 39 & 21 & 17 \\
\hline & TOC & 29 & 31 & 17 & 26 & 19 & 22 \\
\hline & $\mathrm{T}-\mathrm{N}$ & 4 & 14 & 29 & 22 & 22 & 16 \\
\hline & $\mathrm{T}-\mathrm{P}$ & 17 & 21 & 18 & 25 & 23 & 15 \\
\hline \multirow{4}{*}{ Slag C } & COD & 84 & 62 & 62 & 75 & 56 & 69 \\
\hline & TOC & 55 & 92 & 91 & 92 & 91 & 89 \\
\hline & $\mathrm{T}-\mathrm{N}$ & - & - & - & - & - & - \\
\hline & T-P & 76 & 77 & 82 & 64 & 62 & 65 \\
\hline \multirow{4}{*}{ Slag D } & COD & 13 & 13 & 15 & 17 & 15 & 13 \\
\hline & TOC & 12 & 11 & 14 & 13 & 11 & 9 \\
\hline & $\mathrm{T}-\mathrm{N}$ & - & - & - & - & - & - \\
\hline & T-P & - & - & - & - & - & - \\
\hline \multirow{4}{*}{ Dust } & COD & - & - & - & - & - & - \\
\hline & TOC & - & - & - & - & - & - \\
\hline & $\mathrm{T}-\mathrm{N}$ & - & - & - & - & - & - \\
\hline & T-P & - & - & - & - & - & - \\
\hline
\end{tabular}

$\square: 50 \% \leqq)$

\subsection{Change of COD by Bubbling}

Drilling B contained $38.8 \%$ of inorganic-COD and the COD was removed by bubbling. Then, the effect of bubbling was performed on the wastes (Table 4). Though these wastes contained $13.4-40.8 \%$ of inorganic-COD, only $6.5 \%$ (Incineration residue of domestic waste) and $8.3 \%$ (Slag D) of COD were removed by bubbling. On the contrary, 6 and $19 \%$ of COD increased in case of Sludge A and Sludge B, respectively. As the drilling hole water was in anaerobic condition for a long time, much reducing matters generated and corresponded inorganic-COD was removed by bubbling.

\subsection{Coagulation-Sedimentation}

\subsubsection{Removal Ratios with Several Kinds of Coagulant}

Table 5 showed the maximum removal ratios with several kinds of coagulant. In Slag C, relatively high removal ratios (COD: 56-84; TOC: 55-92; T-P: 62-82\%) were obtained with all coagulants. In the other wastes, those of COD, TOC, T-N and T-P were below 39, 31, 44 and 38\%, respectively.

In Incineration residue of domestic waste, Sludge A and Sludge B, the relationship between the removal ratio and the component ratio was examined. Maximum removal ratios of COD, TOC, T-N and T-P were 39, 31, 44 and 38\%, respectively. As $33.8-36.1 \%$ of organic anion-COD was contained (Fig. 3), 7-37\% of COD was removed with the cation-coagulant $\left(\mathrm{FeCl}_{3}, \mathrm{PAC}\right.$ and Aronfloc C-508). Especially, the removal ratios with PAC (24-37\%) were high. The removal ratio with organic cation-coagulant Aronfloc C-508 (7\%) was low. In Sludge A and Sludge B which contained 29.4 and $30.9 \%$ of organic nonion-COD, the removal ratios of $\mathrm{COD}$ with organic nonion-coagulant Accofloc N-11S showed the highest values of 35 and 39\%, respectively. In Incineration residue of domestic waste which contained $7.3 \%$ of organic nonion-COD, 19\% of COD was removed with Accfloc N-100S. But, only $17 \%$ of COD was removed with organic anion-coagulant Accofloc A-150 in spite of containing $43.2 \%$ of organic cation-COD. Though Sludge A and Sludge B contained small amount of organic cation-COD (2.2 and 3.1\%, respectively), 12 and $21 \%$ of COD were removed with Accofloc A-150, respectively. The removal ratio was also affected by the interaction among organic matters.

T-N in Slag C and T-N and T-P in Slag D could not be 
removed or increased by adding the coagulant. As Dust contained much minute carbon particles $(1 \mu \mathrm{m}>)$, the effect of Coagulation-Sedimentation could not observed.

\subsubsection{Influence of Rapid Stirring Speed on Removal Ratio}

The coagulation effect is also affected by stirring speed. The removal ratios of COD, TOC, T-N and T-P were examined with $50 \mathrm{mg} \mathrm{L}^{-1}$ of $\mathrm{FeCl}_{3}$ at $0-350 \mathrm{rpm}$ of rapid stirring speed for Sludge A. But, the ratios were almost same as at $150 \mathrm{rpm}$.

\subsubsection{Influence of the Coexistence with Anion}

The influence of $\mathrm{Cl}^{-}$was examined with $50 \mathrm{mg} \mathrm{L}^{-1}$ of $\mathrm{FeCl}_{3}$ by adding $0-2.0 \mathrm{~g}$ of $\mathrm{NaCl}$ for Sludge A. The ratios of TOC and T-P did not change very much. However, the ratios of COD (19.2\%) and T-N (29.8\%) increased. The effect of salting out is considered. Similarly, the influence of $\mathrm{SO}_{4}{ }^{2-}$ was examined with $50 \mathrm{mg} \mathrm{L}^{-1}$ of $\mathrm{FeCl}_{3}$ by adding 0-2.96 $\mathrm{g}$ of $\mathrm{Na}_{2} \mathrm{SO}_{4}$. The ratio of only T-P $(15.7 \%)$ increased.

\subsection{Activated Carbon Adsorption}

\subsubsection{Adsorption Ratio of Standard Molecular Weight Reagent as TOC}

Figure 5 showed the adsorption ratios of standard molecular weight reagents as TOC with several kinds of activated carbon. Above $90 \%$ of adsorption ratio was obtained on the whole molecular weight in case of Yashicoal S.SC which particle size was the smallest (Table 1). In this column test, particle size largely affected than specific surface area, average fine pore size and fine pore volume. In case of other activated carbon, lower molecular weight reagents hardly adsorbed because they were more hydrophilic. The higher molecular weight is and the higher adsorptivity is because it becomes less hydrophilic. Further, the higher molecular weight is and the lower adsorptivity is because the adsorbate cannot go into the fine pore. The peak was observed in the range of $10^{2}-10^{3}$. In case of Procoal CM and Procoal GN, the peak was also observed in the range of $10^{5}-10^{6}$.

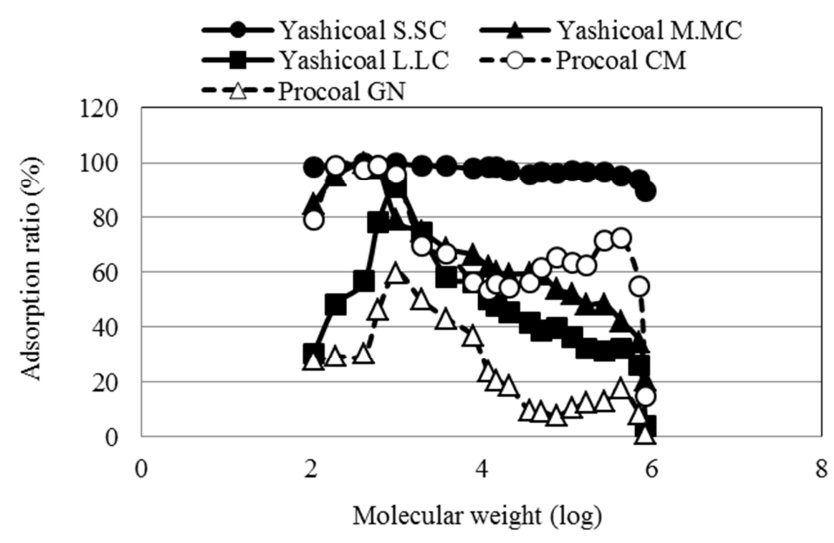

Fig. 5. Adsorption ratio of each standard molecular weight reagent as TOC.

Initial TOC: $10 \mathrm{mg} \mathrm{L}^{-1}, 100 \mathrm{~mL}$; activated carbon: $3 \mathrm{~g}$.

There are a few differences of adsorptivity on each activated carbon for $\mathrm{I}_{2}$, benzene and methylene blue (Table 1).
The reason is that the adsorption test was performed by the batch method [8]. The column adsorption test was performed because the actual treatment was performed by the adsorption tower system. If the solid-liquid separation method such as the sloped-precipitation pipe method [9] would be introduced, the adsorption by the batch method can be performed and the increase of adsorptivity would be expected.

\subsubsection{Adsorption Ratios of Metal Ions}

The adsorption tests of metal ions were performed with Yashicoal S.SC, Yashicoal M.MC and Procoal GN. In case of column adsorption test, the ratios of $\mathrm{Ni}^{+}$and $\mathrm{Fe}^{3+}$ were 100 , 18.4 and $0 \%$ and 52.3, 90.2 and 23.2\%, respectively (Fig. 6). On the other hand, all activated carbons showed $100 \%$ of ratio for $\mathrm{Fe}^{3+}$ in case of jar test. The contact with activated carbon also effects on the ratio in case of metal ions (chemical adsorption).

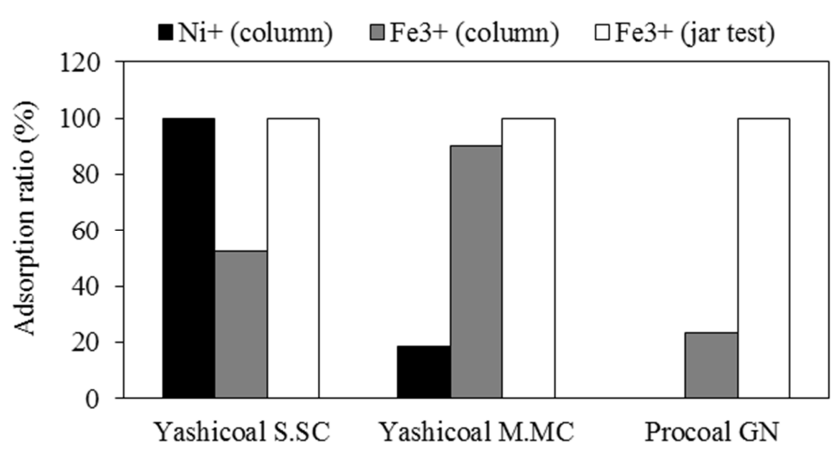

Fig. 6. Adsorption ratio of metal ions.

Initial metal ions: $\mathrm{Ni}^{+} 10 \mathrm{mg} \mathrm{L}{ }^{-1}, \mathrm{Fe}^{3+} 10 \mathrm{mg} \mathrm{L}{ }^{-1}, 100 \mathrm{~mL}$ (column) or $500 \mathrm{~mL}$ (jar test); activated carbon: $3 \mathrm{~g}$.

\subsubsection{Adsorption Ratio of TOC in Wastes}

The column adsorption tests for Incineration residue of domestic waste, Sludge A, Sludge B, Slag C, Slag D and Dust were performed. The adsorption ratios of TOC with Yashicoal S.SC, Yashicoal M.MC and Procoal GN were 55.5-92.7, 51.4-84.9 and 12.5-39.8\%, respectively (Fig. 7). The ratios of TOC in Slag D and Dust were lower. It is also considered that the ratios of TOC in wastes increase by the batch method.

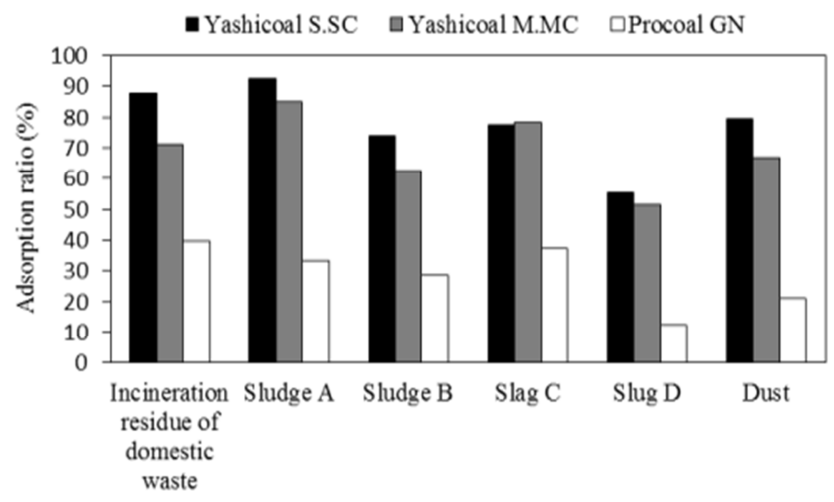

Fig. 7. Adsorption ratio of TOC.

Initial TOC: $10 \mathrm{mg} \mathrm{L}^{-1}, 100 \mathrm{~mL}$; activated carbon: $3 \mathrm{~g}$. 


\section{Conclusion}

In order to treat COD in the wastewater at the sea reclamation waste disposal site effectively, the relationship between COD component and the Coagulation-Sedimentation or the activated carbon adsorption, which were performed at the existing effluent water treatment facility, was investigated.

(1) As the COD except for organic-COD was contained in waste and wastewater, COD value could be reduced by bubbling.

(2) In some waste, COD can be treated effectively by examining the ionic property of organic-COD and using a proper coagulant.

(3) Though the activated carbon adsorption by the batch method was very effective, it is necessary to use the effective solid-liquid separation.

(4) The classification of disposal site for COD treatment like recycling should be considered.

(5) Though the membrane treatment was effective, large amount of concentrated wastewater must be treated [10].

(6) The countermeasures against $\mathrm{Cl}$ - and hazardous substances [11-15] are necessary to discharge into the sewerage.

(7) The introduction of the additional charge system calculated on the effluent treatment cost was considered.

\section{Acknowledgements}

We are grateful to Facilities Management Division, Environment Bureau, Kitakyushu City and Hibikinada Development Co. LTD. for their corporations.

\section{References}

[1] Y. S. Uchimura, Ishikawa, K. Yasuda, Model experiment on the leachate at sea reclamation waste disposal site (II). Water Purification and Liquid Wastes Treatment, 1988, 29(6), 365-370.

[2] M. Hanajima, T. Yamazaki, Y. Matsufuji, Experimental study on the waste reclamation structure. J. of Japan Society of Civil Engineers, 1981, (301), 69-76 (1981) (in Japanese).

[3] Ishikawa, S., Oba, T., Nomura, Y., Ichida, K., Sakazaki, Y., Kojima, T., Fukumoto, M., Suzuki, M., Yanase, R., Tachifuji, A., Matsufuji, Y., Mitsui, K., J. Nakanishi and S. Maeda, Study of leachate purification and waste stabilization at a seaside land reclamation site using a leachate circulation system pilot plant. J. of the Japan Society of Waste Management Experts, 18(2), 107-117 (2007) (in Japanese).

[4] Sakazaki, Y., Inuyama, H., Yamada, T., Oba, T., Ishikawa, S., K Kadokami and M. Suzuki, Application of leachate recirculation landfill technique to coastal landfills, modern landfill technology and management. Proceedings of the Third Asian-Pacific Landfill Symposium in Kitakyushu 2004, pp. 505-512 (2004) (in Japanese).

[5] Japan Industrial Standards Committee, JIS K 0102. Japanese Standards Association, Tokyo, Japan, (2008) (in Japanese).

[6] Japan Environmental Sanitation Center, Method of Waste Disposal Capitular in 2001, pp. 410-428 (2001) (in Japanese).

[7] Japan Society on Water Pollution Research, Guideline for Lake Environmental Survey. Technical Environmental Pollution Control, Tokyo, pp. 151 (1982) (in Japanese).

[8] Japan Industrial Standards Committee, JIS K 1474. Japanese Standards Association, Tokyo, Japan, (2014) (in Japanese).

[9] K. Fujisaki, Enhancement of settling tank capacity with inclined tube settlers. Chemical Engineering, 30(5), 568-573 (2004) (in Japanese).

[10] Yamanaka, K. and S. Ishikawa, Purifier. Patent Number 5563604 (2014) (in Japanese).

[11] Agarwal, B. and C. Balomajumder, Use of coal fly ash for simultaneous co-adsorptive removal of phenol and cyanide from simulated coke wastewater. Sustain. Environ. Res., 23(6), 359-368 (2013).

[12] Wang, C. K., C. W. Hou and Y. X. Wei, Degradation and detoxicity of ethylenediamine wastewater by a continuous dosing mode sono-Fenton process. Sustain. Environ. Res., 23(6), 413-420 (2013).

[13] Mery, J., M. Mendes, L. Mazeas and N. Touze-Foltz, Evaluating the environmental impact of leachate leakage from landfills through aged geosynthetic barrier materials: A focus on phenolic compounds. Sustain. Environ. Res., 24(6), 401-413 (2014).

[14] Barrera-Díaz, C., M. I. L. Meza, C. Fall, B. Bilyeu and J. Cruz-Olivares, Lead(II) adsorption using allspice-alginate gel biocomposite beads. Sustain. Environ. Res., 25(2), 83-92 (2015).

[15] Chen, I. P., C. C. Kan, C. M. Futalan, M. J. C. Calagui, S. S. Lin, W. C. Tsai and M. W. Wan, Batch and fixed bed studies: Removal of copper(II) using chitosan-coated kaolinite beads from aqueous solution. Sustain. Environ. Res., 25(2), 73-81 (2015). 